\title{
Addressing the Impact of Border Enforcement Measures on the Self-Reported Health of Migrants Aiming to Enter Japan During the COVID-19 Epidemic.
}

\author{
Jacques Wels, PhD \\ University College London \\ Faculty of Population Health Sciences, Centre for Longitudinal Studies (CLS), MRC Unit for \\ Lifelong Health and Ageing \\ jcqwels@gmail.com,w.jacques@ucl.ac.uk
}

Version: $2^{\text {nd }}$ of April 2021

https://doi.org/10.31219/osf.io/egq9p

\begin{abstract}
Following the spread of COVID-19 in early 2020, Japan has implemented border enforcement measures to ban most foreigners, including tourists, workers and students from entering Japan for the time being, except for special humanitarian circumstances. For about a year, many migrants have been unable to enter Japan and had to postpone their plans. Using an online questionnaire $(\mathrm{N}=478)$, this study aimed to assess the impact of border enforcement measures on migrants' health and wellbeing. Results indicate that border enforcement measures have generated insecurities, both from a financial and personal point of view. These have had strong negative effects on physical health and, to a greater extent, on sleep quality, level of stress and quality of life. The article demonstrates that insecurity is key for understanding Japanese border policies and, consequently, migrants' health as it shapes a spectrum between the insiders and the outsiders that is determined by factors that take little account of individuals' situation and that the state of exception reveals a gradient that is independent from the epidemic situation. It concludes with five points to be discussed further to protect migrants' heath in case of travel ban: allow a fair treatment of migrants, developing international remote work possibilities, discussing the portability of the costs related to border enforcement measures, allow nonmarried couples to reunite and give a greater visibility to international migrants.
\end{abstract}




\section{Background}

A main consequence of the COVID-19 epidemic was the rapid imposition of national and subnational borders, particularly where cross-boundary openness and integration was prevalent (1) such as in Europe (2) or within the Schengen Area (3) but also in countries where border controls were already in place such as in Australia, Mongolia, Vietnam or Japan, to name a few. As a matter of fact, almost all countries tightened their borders in response to the epidemic (4). This has severely restricted free movement, migration and asylum rights and has been putting into jeopardy refugees' human rights (5). One main issue related to border enforcement measures - but that has not received recent attention - is the impact border closures could have on the health of migrants who were aiming to legally enter a country but had to change their plans or wait for the borders to reopen in a context of huge uncertainty. One thing for sure is that border enforcement measures could be accounted as another side effect of the measures implemented to contain the spread COVID-19 on people's health. A growing number of studies currently underlines the effects of these measures including, to name just a few, the impact of work arrangements on workers physical and mental health $(6,7)$, the gender discrepancies in health outcomes $(6,8-10)$ or the long-term consequence of the epidemic on mental health, suicide rates, violence and so on (11). Among these effects, migration control is a major concern though it is often viewed under the framework of access to health system (12) and social security in the host country or when moving back to the country of origin (13). No studies have looked at the situation of those affected by border enforcement implemented since February 2020 even though the relationship between internal (14) and international mobilities and the spread of COVID-19 is largely discussed in the recent literature $(15,16)$. Migrant workers are, indeed, those who could be the most affected by the COVID-19 situation (17) both because they are more likely to lose their job because of business closures but also because they might not be able to enter or re-enter the country where their employment is. This is also 
the case of international students who could be the most vulnerable when no accurate support is provided by their host country $(18,19)$ but could also struggle to join the country where they intend to study. Finally, the current situation is also about couples and families who have not been able to reunite in countries that have strictly tighten up their borders policy.

The case of Japan is a relevant example of strict border enforcement measures that affected these three categories of migrants. Over the past decade, the number of foreign residents has increased in Japan (20), which reflects a big change for a country that has always had a low non-native population and has very gradually implemented arrangements to welcome, based on strict criteria, newcomers, particularly on a skills basis (21) but still on a very limited number (22). The increasing rate of foreigners in Japan has been reversed temporarily in February 2020 following a sharp increase in detected COVID-19 cases and the decision by the Japanese Government to temporarily and partially close its borders to international migrants, including long-term residents at first (23). The practical background about travel restrictions to Japan can be shortly summarized as in figure 1 . On the $16^{\text {th }}$ of April 2020 Japan has declared a State of Emergency for several prefectures including Hokkaido and the Tokyo area. The State of emergency ended on the $25^{\text {th }}$ of May 2020. At the same time, Japanese authorities have implemented a travel ban for most travelers from all around the world that applied to tourists, students and workers. On the $1^{\text {st }}$ of October 2020 (about 6 months after the start of the first State of Emergency), Japan implemented phased measures for resuming cross-border travel for workers and students with compulsory quarantines of 14 days (24), PCR tests (before and after boarding), daily health monitoring for 14 days and follow-up by the institution in charge of the migrant (school, institution or business) through a written pledge involving the responsibility of the host institution in case migrants were breaking the rules. In late December and due to the spread of newly detected COVID-19 variants, the Japanese authorities decided to close the borders to some countries particularly affected by these variants and, in January 2021, phased 
measures for resuming cross-border travel were stopped until the end of the second state of emergency that was declared on the $7^{\text {th }}$ of January 2021 (25) and was further extended until late March 2021 with further travel restrictions to follow. This practically translates into two travel bans for migrant workers and students: a first border enforcement of six months between April 2020 and October 2020 and an ongoing travel ban since January 2021 with no certainty so far about what is going to happen next. The only window for workers and students to travel to Japan over the last year was between October 2020 and December 2020. Consequently, it can be assumed that many potential migrants to Japan, including workers under short to midterm visa and students, have been affected by the current situation and had to postpone their stay. Non-native residents were banned entering in Japan for a few months after the start of the first wave but those who are already long-term residents have been gradually allowed to move back to their home country. By contrast, those who were granted residency but have not moved to Japan before the start of the epidemic were banned from entering Japan.

\section{[Please, insert figure 1]}

Border enforcement measures could be clearly considered as the apparatus of a state of exception - that one would call nowadays a State of emergency - that relies on an opposition between the insiders and the outsiders but also generates a differential treatment between those who are in and those who are out. Interestingly, border enforcement measures could be seen as the consequence of the State of Emergency, but they go much beyond what is imposed to the local population. This raises the question of sovereignty when looking at border enforcement measures. Sovereignty is at the heart of the state of exception, but it appears that there is a gradation in the way it applies. Exception, in this case is therefore nothing else than a form of exclusion (26): "what is excluded is not without relationship with the norm; in contrary, the norm remains with it in the form of its suspension" (p.25). But the exclusion is gradual, and the spectrum of its intensity is the responsibility of the sovereign State. This results in a 
differential treatment by the established of those who are characterized as outsiders - one refers here to the work carried out by Elias and Scotson (27) about an anonymous English town in the 1960 s - , independently from their race, ethnicity or social position. A racism without a race. But for this racism without race to be efficient, and as there is an obvious gradient between what is an insider and what is an outsider, the apparatus of the state of exception needs to rely on uncertainty: uncertainty as a policy that deal with the full gradient and set up priorities without defining what the priorities are. To make it simple: How to distinguish the native national from the long-term resident? How to distinguish the emeritus professor from the student? How to distinguish the married couple from the unmarried couple? The definition of the gradient between established and outsiders, that is the basis of a 'normal' visa policy is, when comes the state of exception, subject to uncertainty. Residency, short-term residency, and studentship are many aspects of what not being a national is and they also are those who, in a state of exception, are excluded from a norm that, de facto, excluded them in advance. But paradoxically, in the current context, and as the health protection of Japanese residents is the key factor for implementing a travel back, health is the justification of such an apparatus, but it is also one of its consequences; for protecting the insiders, the state of exception threatens the outsiders. How? Border enforcement measures take the form of a legal set of instruments that lies on a certain idea of uncertainty that puts non-native Japanese citizens in limbo and affects their study, career and relationship.

Such an uncertainty generates a great feeling of unfairness within migrant communities. This could be understood easily though very simple example. Whilst migrants who have got a job offer in Japan and were granted a residency permit have been banned from entering Japan for almost a year with no long-term perspective about what is going to happen next, Japanese citizens living abroad and who have never worked in Japan were allowed to move back to their country with no trouble at all. Both uncertainty and feeling of unfairness have had a massive 
impact on migrants' health. The relationship between border enforcement measures and migrants' health is the natural consequence of a state of exception that distinguishes those who can enter and those who cannot, independently from any bilateral or multilateral negotiation. But what is specific to the state of exception is that it occurs exceptionally, in a way that was not fully planned neither for the State, nor for the individuals. Border closures are embedded within individuals' trajectories and shape these trajectories in many ways. Such phenomena have been identified by previous studies, albeit in a very different context. Studies on the relationship between border enforcement measures and migrant's physical and mental health are very few in number. Most studies focus on the inside migrant population already residing within the territory where border enforcement measures are implemented and a significant number of studies focus on the impact of state-level immigration restrictions in the United States (28). That is the case, for instance, of Latino immigrants in Arizona (29) that have declared a greater personal suffering as a consequence of Anti-immigrant policies and enforcement strategies and have reported significantly higher symptoms of depression, anxiety, and stress or in California (30) where immigration legislations have had an impact on the social determinants of health including economic stability, education, health and access to care. Results are significant from one study to another with border enforcement measures that correlate with a poorer mental health (31) and are independent from whether respondents are US-born citizens or not (32). Results are similar at cross-state level as individuals in states with a more exclusionary immigration policy climate had higher rates of poor mental health (33). From a qualitative point of view, border enforcements have concrete effects on fear of deportation and concerns about not being able to furnish documentation required to apply for insurance and health care (34) and mistrust in health services (35). One key element that generates adverse physical and mental health effects is the uncertainty about the timing and the rules associated with border enforcement measures. The recent situation has shown that 
countries were more likely to minimize the challenges of international migration instead of addressing them with, in the case of Japan, little information available for migrants (23) and a high degree of uncertainty that translate into a lack of trust for the Japanese Government and the local immigration agencies (36).

Against this backdrop, the purpose of this study is to assess to what extent uncertainties created by border enforcement measures implemented in Japan have had adverse health effects on the health of migrants aiming to enter Japan.

\section{Data and methods}

\section{Data collection}

The specificity of the study is that it does not target a population that already resides within the host country but rather the population that aims to enter this country but was not able to. To do so, data had to be collected as there is no available existing data on this matter in the case of Japan, particularly for a population that has not reached the country yet. The survey was conducted between the $2^{\text {nd }}$ of March and the $4^{\text {th }}$ of March 2021 through an online questionnaire spread via social media such as Facebook, Twitter and Reddit, primarily through online groups bringing together individuals preoccupied by the current Japanese immigration policies $(\mathrm{N}=478)$. The answers rate was surprisingly high as it reached 260 respondents 13 hours after the launch of the study which clearly indicates a great reactivity of respondents that can be imputed to the current context of uncertainty. Answers should be considered as representative of the current mindset of those aiming to enter Japan or those who have entered Japan since April 2020. Three reasons explain the choice of a snap survey. First, there is obviously no data about the health and wellbeing of migrants who cannot enter countries that have implemented a travel ban and Japan authorities do not communicate descriptive statistics about these populations. Second, collecting data over a limited amount of time was necessary because the information provided by Japanese authorities as well as the news spread by English and 
Japanese speaking medias could have an impact on the perspective respondents would have about travel enforcement measures. Finally, it has to be mentioned that instead of comparing the group of interest with a control group (which would be been impossible in this specific case), this study performs analyses on the group of interest distinguishing the impact of a specific set of variables on the differences in self-reported health indicators.

\section{Dependent variables}

It was asked within the survey whether border enforcement measures have had negative effects on physical health, quality of life, sleep quality and stress level. For those declaring that it had an impact, a second question was asked about the intensity of this impact, calculated on a Likert scale, from 'very low' to 'very high'. Combining the two types of questions allow to create four variables ranging from 1 (no impact) to 6 (high impact). However, the distribution of these variables leads up to question how they could be interpreted in a regressive model (figure 2). To simplify the interpretation as well as for making the categories more consistent, the variables were recorded on a three modalities scale ranging from "no change or positive change (0)' to 'slightly negative change (1)' and 'strong negative change (2)'.

\section{Explanatory variables}

To better understand the relationship between travel enforcement measures and health indicators, the study controls for a set of covariates distinguishing four aspects that could possibility explain health variations across the population. A first aspect looks up at individuals' characteristics and account for age, gender (ref.: female), highest level of education (ref.: Bachler, undergraduate), current status of occupation (ref.: work) and principal reason for planning to move to Japan (ref.: work). A second aspect refers to social relationships in Japan and includes two variables that distinguish respondent based on whether they have friends in Japan (ref.: no friends) and whether they have a partner (including girlfriend or boyfriend) or a spouse in Japan (ref.: no partner). The third aspect looks at the individual's self- 
perceived financial situation. Two variables are used. The first variable assesses the selfreported level of wealth one year prior the survey (from 1: very poor to 5: very wealthy) and the second assess whether the travel ban has had negative consequences (from 0: no consequence to 10: strong consequences). Finally, a set of variables estimates the level of individual's uncertainty. First it was asked whether the respondents had received a certificate of eligibility $(\mathrm{CoE})$ within the year. Second, it was asked whether respondents were positive, negative or did not know about what would happen in the coming month (ref.: positive). Third, a last question was about previous histories of being a resident or tourist in Japan.

\section{Models}

Most respondents have reported a negative change in their health and life quality but with different levels of intensity. Therefore, the model used in this study aims to point out the cofounders that principally relate to a strong negative change versus a medium change or no change (or a positive change). Ordered logit regression is the most accurate way to do so as the estimates are in proportional logit (37). In other words, the model estimates the proportional log odds of declaring a strongly negative impact on physical health, quality of life, sleep quality and level of stress in relation with the set of independent variables. Two approaches could be used to do so: the original ordered logit model that is based on a logit distribution and the Bayesian ordered logit approaches that lies on a Dirichlet distribution (38). Both approaches were tested for this study with no significant differences. Only the results from the Bayesian perspectives are presented in this article.

To better understand the estimates, the results section of this article is divided in three subsection. First, one shortly presents some descriptive statistics of the main characteristics of the sample. Second, estimates from the Bayesian ordered logit regression are discussed. Finally, a third sub-section present additional descriptive statistics flowing from the study but also pay attention to the comments made by the respondent in the open comments section of the survey 
as they contribute to enlighten how uncertainty has contributed to damage respondents' health by focusing on the 'stories' experienced by the respondents, in a more qualitative way (39).

\section{Results}

\section{Descriptive statistics}

Respondents' ages range from 18 to 61 with a mean at 28.25 and a median at 26 which indicates a relatively young population. This is mainly due to the high proportion of students who answered the survey. Gender is almost equally reported with a proportion of 44.5 percent of male respondents and 52 percent of female respondents (3.5 percent of the sample declared 'other' or 'prefer not to say'). The main self-declared current statuses of occupation are employed (40.7 percent), student (21.6 percent) and unemployed (24.5 percent). Information was collected about the country of current residence (at the time of the survey) and the country of nationality (dual nationality was not allowed here) with almost similar distribution. The main respondents' countries of nationality are shown in table 2 and compared with to total stock of migrants in 2017 (World Bank data). This indicates an overrepresentation of US and UK citizens within the survey and no respondents from the main migration corridors to Japan (China and South Korea).

\section{[Please, insert table 1]}

The maximum level of education ranges from no education to $\mathrm{PhD} /$ doctorate with a majority of respondents holding a bachelor from a higher education institution (half of the sample). This is another major limitation of the study: the sample tends to include those with high levels of education with very few respondents with primary or secondary education only (7.5 per cent). Among this sample, some have already been to Japan before (74.1 percent) under a status of resident (for 53.8 percent of them) or under a tourist status (46.2 percent). 83.5 percent of the sample has friends in Japan, 30.4 percent has a partner, spouse or boyfriend / girlfriend in Japan. These partners are of Japanese nationality for 70.6 percent of them. There are many 
reasons why respondents planned to be in Japan, but three major reasons pop out of the survey: for study purpose (23.3 percent), to fill a position in the private sector (14.1 percent) or in the public sector (16.7), for family reasons (12 percent) and to carry on with research, teaching or educational activities (16.9 percent). 6.1 percent of the sample declared needing to be in Japan for personal reasons.

\section{[Please, insert figure 2]}

As can be observed in figure 2, different patterns exist depending on the health variable we are looking at. Quality of life and level of stress are the most polarized variables with a high proportion of the sample declaring a slight negative change (-1) or a strong negative change (-

2) and few respondents declaring no change (0) or a positive change $(>0)$. Change in sleep quality and physical health are more balanced with a relatively high proportion of respondents declaring no change.

\section{Bayesian Ordered Logits Model}

Results flowing from the ordered logit model under a Bayesian framework are shown in figure 3. The figure exhibits the estimates (in log odds) for the full set of covariates as well as for the cut points (two cut points for three modalities) for the four dependent variables (physical health, quality of sleep, quality of life and level of stress). The figure also includes the confidence intervals calculated at 95 per cent (the thin lines) and at 90 per cent (the thick lines). Four main observations can be made based on the different dimensions mentioned above.

\section{[Please, insert figure 3]}

First, the figure clearly indicates that social relationships have an impact on health when it comes about having a partner or a spouse based in Japan but not when looking at whether respondents have friends in Japan. Having a partner based in Japan is associated with higher 
levels of stress $(0.43, \mathrm{SD}=0.22)$, lower sleep quality $(0.37, \mathrm{SD}=0.21)$, lower quality of life $(0.49, \mathrm{SD}=0.22)$ and poor change in physical health $(0.39, \mathrm{SD}=0.23)$. Results are not significantly different for those having a spouse, but estimates are not significant for stress level.

Second, uncertainty is a key factor in explaining health discrepancies among stranded migrants. Having been formally allowed to enter Japan through a so-called Certificate of Eligibility $\mathrm{CoE}$ but not being able to get a visa is associated with higher level of stress and lower sleep quality with estimates reaching respectively $0.18(\mathrm{SD}=0.17)$ and $0.24(\mathrm{SD}=0.15)$. Similarly, being pessimistic - as more than a third of the sample is - is a factor associated with stress, sleep quality, quality of life and physical health once compared with people who do not know about the future of border enforcement measures. Estimates for those being pessimistic are, respectively, $0.28(\mathrm{SD}=0.20), 0.34(\mathrm{SD}=0.19), 0.32(\mathrm{SD}=0.19)$ and $0.30(\mathrm{SD}=0.19)$. By opposition, optimism, compared with not knowing, is associated with lower propensities of declaring a negative change in health, but only significant at 95 per cent in the case of stress level $(-0.30 ; \mathrm{SD}=0.20)$ and at 90 per cent in the case of physical health $(-0.26 ; \mathrm{SD}=0.19)$. The association between the past status of residence in Japan and health is another interesting dimension to look at. The survey distinguishes respondents based on whether they have already been to Japan prior the travel ban, and under which status of residence. The model compares those who have visited Japan under a tourist visa (34 percent), a short-term residency (20 percent) or a long-term residency permit (19 percent) with those who have never been to Japan (27 percent). Despite low significance levels for sleep quality and quality of life, it can be observed, when taking into consideration a 90 percent confidence interval, that respondents who have previously held long and short-term residency permits have lower odds of declaring a negative change in stress level and, but to a lesser extent, physical health compared with those who have never been to Japan before. This seems to indicate that those with an history in Japan 
are bounded to Japan in a way and that the connection they have with the country might be less porous to border enforcement measures.

Third, the self-rated financial situation on year ago is not a factor significantly associated with poor health outcomes, but the changes created by border enforcement measures on individuals' financial situation are. Independently from the level of occupation or the type of current occupation, a degradation in financial situation is clearly a factor explaining negative health outcomes: an increase in the scale of negative effects of border enforcement measures on individuals' financial situation is associated with higher logits by $0.32(\mathrm{SD}=0.11)$ for physical health, $0.35(\mathrm{SD}=0.11)$ for quality of life, $0.33(\mathrm{SD}=0.10)$ for sleep quality and $0.31(\mathrm{SD}=0.11)$ for stress level. Adverse financial effects are strongly associated with negative change in health outcomes, independently from the level of uncertainty, previous financial differences or previous histories in Japan.

Finally, individuals' characteristics do not contribute to significantly explain the health differences observed across individuals. Age and gender are not significancy associated with changes in health and quality of life and the level of education seems to indicate a positive impact of being highly education versus having no formal education, but results are barely significant.

\section{Addressing uncertainty, unfairness and migrants' health}

The last section of the survey allowed respondents to give a comment about their current situation (Do you have further comments or things you would like to share about the current situation?). About half of the respondents made a comment, for a total of 10.691 words, which gives a more personal overview on the data that were presented above. A first observation flowing from these comments is that border closure interacts with migrants' life course as a 
turning-point (40) they have no control on. On the one hand, travel ban compromises arrangements that have been taken and put quality of life in jeopardy:

"I've been waiting for a year to enter. Got my COE in December but the borders closed as soon as the embassy got my visa application. I was supposed to leave Jan 15th so I sold my car, ended my apartment lease, and ended contracts and my job. It's been 2 months and I have no idea when I am going to go. No communication at all. I'm stressed, I don't sleep, my whole future is up in the air. I have to find a new place to leave in the meantime as well as pay for my apartment in Japan. Please Japan let us know what is happening with borders. " (Respondent A)

On the other hand, it also has an impact on professional careers that could last beyond border enforcement:

"When I applied for my [...] Scholarship, I was 28 now I am 30 it is waste of time and makes me feeling upset" (Respondent B)

Such a feeling is also imputed to the lack of flexibility of the institutions in Japan (employment, schools or universities) that have not been able to provide remote work or online teaching or took a long time before implementing these solutions and the Japanese authorities which have implemented costly measures for migrants entering Japan:

“[name of the scheme] Scholars won't receive the monthly stipend if we are not in Japan and taking online classes, which would make it very unfair because this was out of our control. Moreover, [name fo the scheme) gave the option of deferring to April 2021 and promised that there would be equal treatment for both options. [...] We are also required to stay in a hotel instead of any private housing which makes it more expensive for us. If they're not going to pay for it, at least let us choose our housing for two weeks" (Respondent C)

The travel ban is seen as unfair by many respondents, particularly because Japan has had opened a discussion about opening borders for athletes and their teams prior allowing students and workers to enter the country. This sense of unfairness is somehow increased by home 
countries' situations and epidemic control. As Japan is often regarded as a safer country in terms of epidemic control.

"The recent news that Olympics athletes will be allowed entry this month has been upsetting. I along with several of my peers have had our employment in Japan delayed by both border lockdowns. People quit their jobs expecting to be in Japan in January and now many people are in a dangerous financial situation as jumping back into work now runs the added risk of contracting COVID-19 with the increase in my country's cases." (Respondent D)

"[...] It has greatly impacted my mental health and it has showed an explicit discrimination from the Japanese government, especially considering the treatment that the Olympics athletes will receive $[\ldots]$ "... Respondent $E)$

"The travel ban has severe negative consequences on my mental health (depression). Infant son is Japanese and with me and we cannot be reunited with my Japanese husband" (Respondent F)

But in most cases, what popped out from the different comments is the combination of different factors in explaining migrants' health. Uncertainty, financial adversity and social relationships are affected by border enforcement measures and reinforce each other.

"I had my wedding delayed 3 times. because of the travel ban and once $i$ did succeed to get wedding done in my home country $i$ got stuck in there and almost lost my job in tokyo. now $i$ have been unable to get reunited with my wife for more than 6 mont. spent 2 weeks as newly married couple with her and then 6 months alone in my apartment talking through zoom and the fact that border opening date get delayed each month make me depressed $i$ wish they say we are going to open in 2022 than $i$ can leave the country and go work in my home country but they don't they keep saying next month next month .... and. in. the meantime $i$ am dying here with depression, anxiety and loneliness" (Respondent G)

"I used to have a Japanese partner of over a year, but because she didn't know when, if ever, I would be able to come, she decided to break up with me six months into the ban. I also have had to move back in with my parents. I have had to stay unemployed because of the month-by-month 
communication. No one wants to hire me for temporary work because I cannot give them an estimate timeline of how long I'd be able to stay" (Respondent H)

Comments from respondents $\mathrm{G}$ and $\mathrm{H}$ clearly indicate the interaction between personal relationships (a spouse or a partner), financial instability and the uncertainty created by border enforcement measures with adverse effects on mental health.

\section{Limitations}

The study has five main limitations. First, the survey contains a limited number of countries, excludes the main migration corridors with Japan (i.e., with China and South Korea) and contains a high proportion of US and UK citizens. No consistent information about South-East Asian countries was collected and it is likely that the study does not capture the case of migrants selected on a 'skill' basis. Second, the sample size is relatively small but cannot be compared with official data as the number of migrants waiting to enter Japan has not been communicated. Consequently, data were not weighted. Third, data were collected in a context of high uncertainty, whilst Japan was discussing whether it would extend the State of Emergency (and, therefore, border enforcement measures) at the time the survey was made. Fourth, the study contains a few respondents (8) who declared having children in Japan but were not able to enter anyway. This is a humanitarian issue, particularly because the access to Japan for these people is basically allowed. There is a need to look further at these specific cases. Finally, respondents contact details were collected, which will allow a second wave to be run to collect longitudinal information about change in health and immigration process.

\section{Discussion}

To control the spread of COVID-19, many countries have implemented border restriction measures. Whilst these measures principally target tourism, some countries have implemented broader border enforcement to ban all kinds of travelers including workers, students and 
families with exceptions for humanitarian reasons. Among these countries some have implemented a so-called travel ban that applies to a majority of countries and citizens, independently from the reasons why they are travelling. Consequently, many migrants had to delay their stay and are often let in limbo with no clear information about further border opening. Japan is a very specific case as it has implemented strict measures to reinforce border restrictions for foreigners, a slight control on Japanese nationals and a three-month attempt to progressively reopen borders that was then stopped by a second epidemic wave. All this within a context of high tension related to the organization of the postponed 2020 Olympics.

Discussing whether the decision to close the borders was justified or not was not the purpose of this article - even though an emerging literature seems to indicate that border closure would delay but not contain (16) the spread of the epidemic. Instead, the study aimed to underline the main effects of border enforcement measures on the health of migrants aiming to enter Japan. The damages are obvious and expected, but the study clearly indicates that personal relationships (having a partner in Japan), income loss, and, more fundamentally, uncertainty have detrimental effects on self-reported physical and mental health and on quality of life. These findings put into evidence several deficiencies in the way migrants have been treated by Japan and, to a lesser extent, in the way they have been protected by their origin country.

First, the article shows that trust and fairness when it comes about international relationships and bilateral agreements with Japan have to be discussed further as the state of exception underlines a clear differential treatment of migrants based on factors that are not all related to migration as such. One the one hand, trust has become a main challenge for many migrants as many of them now do not have any confidence in neither the Japanese government nor the local immigration authorities. Many migrants disagree but understand in a way border closure but the lack of transparency and communication about a proper timing for opening has had adverse effects on trust. On the other hand, border enforcement measures take place in the very 
particular context of the postponed 2020 Olympics and Paralympics that will take place during summer 2021. Japan has made clear that this was a top priority and that, even though foreign spectators would not be allowed, it plans to open up the spectrum of special circumstance measures for international travel to sportsmen and sportswomen and their teams. This generates a sense of unfairness for migrant workers and students and a feeling that the economy, education and research have been scarified to organize the Olympics. Therefore, the gradient between who is an outsider and who is an insider is a clear function of the economic immediate benefits for Japan that should question the benefits of encouraging workers and students to move to Japan in the future.

Second, it is necessary to insist on the fact that little was done to push toward remote work and remote study when looking at international migrants. Even though many countries, including Japan, have implemented home working schemes during the epidemic, few are the respondents who have had access to remote work whilst they were waiting for the Japanese borders to reopen. Even though the survey points out that migrants have a high level of trust in their host institution (compared with what they think about the Japanese government), international remote work is a field that could be explored further to protect migrants even though it raises many issues in terms of incomes transfer, data protection and working conditions. One thing for sure is that the state of mind was more about waiting for the border to reopen than implementing concrete solutions for international workers and students to start their activity from abroad. Japan used limbo as a migration policy for more than a year and did not give the opportunity to the institution to organize themselves.

Third, a main issue that has not been addressed so far are the cost related to border enforcement measures for the origin country. Losing a job or postponing the start date of the contract due to border closure has become the norm for migrants who aimed to enter a country that has implemented a travel ban. Consequently, it can be expected that a majority of migrant workers 
had to rely on their savings (if any) or on social protection in their country of residence (if any). This generates costs for the host countries that are not borne by Japan. A framework to evaluate and make possible potential financial transfers exists through bilateral social security agreements (41-43), and Japan have signed many of them over the past decades. Border enforcement measures are a national policy that has effects on the local economy but also international development. The costs related to border closure are easy to estimate at an individual level or on a lump sum basis, but one should also pay attention to the costs related to healthcare as, as demonstrated in this article, the health of migrants has been affected.

Fourth, from a more general point of view, there is a clear need to discuss further the place of marriage when looking at international migration in a configuration of border restrictions. So far, Japan has progressively allowed permanent residents to move back to Japan (they were banned for a few months after the so-called first wave of COVID-19 in February 2020) whilst nationals have always been free to move in and out. In such a configuration, no discussion has taken place about partners, girlfriends and boyfriends and this creates an environment where civil marriage is the only way for those to have both freedom and security. But again, civil marriage works only if one of the spouses is a Japanese national. The state comes to play a part in personal relationships (44) and what could be implemented to protect relationships is certainly something to discuss further.

Finally, it has to be said, to conclude, that little visibility has been given to international migrants during the COVID-19 pandemic and, so far, no international study has assessed the changes in border enforcement that have been implemented by many countries. Such a comparison is hard because the length of border enforcement measures such as the categories of migrants that were banned vary from one country to another. If tourism was first type of migration to be banned in most countries or territories, an overview of travel ban for migrant workers and students is so far not available. And this translates into a silence and a certain form 
of blindness on individuals' situations. Whilst professional and personal lives are at stake, few are those who communicate about what has been happening since the start of the COVID-19 pandemic even though it concerns a substantial amount of people and generates important detrimental effects on their health. 


\section{References}

1. Radil SM, Castan Pinos J, Ptak T. Borders resurgent: towards a post-Covid-19 global border regime? Sp Polity [Internet]. 2020;0(0):1-9. Available from: https://doi.org/10.1080/13562576.2020.1773254

2. Heller C. De-confining borders: towards a politics of freedom of movement in the time of the pandemic. Mobilities [Internet]. 2021;16(1):113-33. Available from: https://doi.org/10.1080/17450101.2021.1873563

3. Carrera S, Luk NC. An Assessment of the Schengen Internal Border Controls and Travel Restrictions in the EU P. IPOL | Policy Dep Citizens' Rights Const Aff List. 2020;PE 659.506:178.

4. Guadago L. Migrants and the COVID-19 pandemic : An initial analysis. Migr Res Ser [Internet]. 2020;(60):1-28. Available from: Lorenzo

5. Ramji-Nogales J, Goldner Lang I. Freedom of movement, migration, and borders. J Hum Rights [Internet]. 2020;19(5):593-602. Available from: https://doi.org/10.1080/14754835.2020.1830045

6. Wels J, Hamarat N. Are employment arrangements implemented during the first wave of COVID-19 associated with better health outcomes for women aged 55 and over? METICES Discuss Pap Ser. 2021;3:17.

7. Wels J, Hamarat N. Work and Employment Arrangements Europe and their Relationship with the aged 55 and over . Results from SHARE . METICES Discuss Pap Ser. 2021;(2):21.

8. Alon T, Doepke M, Olmstead-Rumsey J, Tertilt M. The Impact of Covid-19 on Gender Equality. NBER Work Pap Ser. 2020;26947:39.

9. Farré L, Fawaz Y, González L, Graves J. How the COVID-19 lockdown affected gender inequality in paid and unpaid work in Spain. IZA Discuss Pap. 
2020;13434(13434).

10. Cook R, Grimshaw D. A gendered lens on COVID-19 employment and social policies in Europe. Eur Soc [Internet]. 2020;0(0):1-12. Available from:

https://doi.org/10.1080/14616696.2020.1822538

11. Ioannidis JPA. Global perspective of COVID-19 epidemiology for a full-cycle pandemic. Eur J Clin Invest. 2020;50(12):1-9.

12. Mitchell R, Nou G. Migrants: Left behind in health. Lancet Reg Heal - West Pacific. 2021;7:100119.

13. Holzmann R, Wels J. The cross-border portability of social security benefits: Status and progress? Int Soc Secur Rev. 2020;73(1):65-97.

14. Oh J, Lee HY, Long KQ, Markuns JF, Bullen C, Barrios OEA, et al. How well does societal mobility restriction help control the COVID-19 pandemic? Evidence from real-time evaluation. medRxiv. 2020;

15. Hossain MP, Junus A, Zhu X, Jia P, Wen TH, Pfeiffer D, et al. The effects of border control and quarantine measures on global spread of COVID-19. medRxiv. 2020;1-24.

16. Wells CR, Sah P, Moghadas SM, Pandey A, Shoukat A, Wang Y, et al. Impact of international travel and border control measures on the global spread of the novel 2019 coronavirus outbreak. Proc Natl Acad Sci U S A. 2020;117(13):7504-9.

17. Kikkawa Takenaka A, Villafuerte J, Raymond Gaspar, Badri Narayanan. COVID-19 Impact on International Migration, Remittances, and Recipient Households in Developing Asia [Internet]. Vol. 0. 2020. Available from: http://dx.doi.org/10.22617/BRF2002192\%0Ahttps://www.adb.org/sites/default/files/publication/622796/covid-19-impactmigration-remittances-asia.pdf\%0Ahttps://www.adb.org/publications/covid-19impact-migration-remittances-asia 
18. Firang D. The impact of COVID-19 pandemic on international students in Canada. Int Soc Work. 2020;63(6):820-4.

19. Nguyen O (Olena) TK, Balakrishnan VD. International students in Australia-during and after COVID-19. High Educ Res Dev. 2020;39(7):1372-6.

20. UNICEF. Migration Profiles. Japan [Internet]. 2013. 4 p. Available from: https://esa.un.org/miggmgprofiles/indicators/files/Japan.pdf

21. Oishi N. Skilled or unskilled?: The reconfiguration of migration policies in Japan. J Ethn Migr Stud [Internet]. 2020;0(0):1-18. Available from: https://doi.org/10.1080/1369183X.2020.1731984

22. Castillo Lozano DA. How immigration can boost the Japanese economy by mitigating the effects of population aging. Mundo Asia Pacífico. 2020;9(16):105-17.

23. Bekeš A. Dissonance: Coexistence with Foreigners vs. Coronavirus Epidemic Countermeasures in Japan. Inter Fac [Internet]. 2021;10(2020):55-75. Available from: https://doi.org/10.15068/00162391

24. Looi MK. Covid-19: Japan ends state of emergency but warns of "new normal." BMJ [Internet]. 2020;369(May):m2100. Available from: http://dx.doi.org/doi:10.1136/bmj.m2100

25. Looi MK. Covid-19: Japan declares second state of emergency as Asia struggles with virus surge. BMJ. 2021;372(January):n141.

26. Agamben G. State of Exception [Internet]. Chicago: The University of Chicago Press; 2005. Available from: http://en.booksee.org/book/827643\%0Apapers2://publication/uuid/B4F80A22-83934F66-97BE-7DF5B03D05FE

27. Elias N, Scotson JL. The Established and the Outsiders. Fayard; 1965.

28. Hardy LJ, Getrich CM, Quezada JC, Guay A, Michalowski RJ, Henley E. A call for 
further research on the impact of state-level immigration policies on public health. Am J Public Health. 2012;102(7):1250-4.

29. Becerra D, Hernandez G, Porchas F, Castillo J, Nguyen V, Perez González R. Immigration policies and mental health: examining the relationship between immigration enforcement and depression, anxiety, and stress among Latino immigrants. J Ethn Cult Divers Soc Work [Internet]. 2020;29(1-3):43-59. Available from: https://doi.org/10.1080/15313204.2020.1731641

30. Gurrola MA, Ayón C. Immigration Policies and Social Determinants of Health: Is Immigrants' Health at Risk? Race Soc Probl [Internet]. 2018;10(3):209-20. Available from: http://dx.doi.org/10.1007/s 12552-018-9239-z

31. Wang JSH, Kaushal N. Health and Mental Health Effects of Local Immigration Enforcement. Int Migr Rev. 2019;53(4):970-1001.

32. Szkupinski Quiroga S, Medina DM, Glick J. In the Belly of the Beast: Effects of AntiImmigration Policy on Latino Community Members. Am Behav Sci. 2014;58(13):1723-42.

33. Hatzenbuehler ML, Prins SJ, Flake M, Philbin M, Frazer MS, Hagen D, et al. Immigration policies and mental health morbidity among Latinos: A state-level analysis. Soc Sci Med [Internet]. 2017;174:169-78. Available from: http://dx.doi.org/10.1016/j.socscimed.2016.11.040

34. Hacker K, Chu J, Leung C, Marra R, Pirie A, Brahimi M, et al. The impact of Immigration and Customs Enforcement on immigrant health: Perceptions of immigrants in Everett, Massachusetts, USA. Soc Sci Med [Internet]. 2011;73(4):58694. Available from: http://dx.doi.org/10.1016/j.socscimed.2011.06.007

35. Rhodes SD, Mann L, Simán FM, Song E, Alonzo J, Downs M, et al. The impact of local immigration enforcement policies on the health of immigrant Hispanics/Latinos 
in the United States. Am J Public Health. 2015;105(2):329-37.

36. Wels J. Assessing the Effects of Border Enforcement Measures Since the Start of the COVID-19 Pandemic on Migrants Aiming to Enter Japan. Preliminary Descriptive Report (Version 1 - 4th of March 2021). METICES Discuss Pap Ser. 2021;4:23.

37. Winship C, Mare RD. Regression Models with Ordinal Variables. Am Sociol Rev [Internet]. 1984;49(4):512-25. Available from: http://www.jstor.org/stable/2095465?origin=crossref

38. Sha N, Dechi BO. A Bayes Inference for Ordinal Response with Latent Variable Approach. Stats. 2019;2(2):321-31.

39. O'Cathain A, Thomas KJ. "Any other comments?” Open questions on questionnaires A bane or a bonus to research? BMC Med Res Methodol. 2004;4:1-7.

40. Abbott A. Conceptions of time and events in social science methods: Causal and narrative approaches. Hist Methods. 1990;23(4):140-50.

41. Holzmann R, Wels J. Status and Progress in Cross-Border Portability of Social Security Benefits. IZA Inst Labor Econ Discuss Pap Ser [Internet]. 2018;(11481):27. Available from: https://www.iza.org/publications/dp/11481/status-and-progress-incross-border-portability-of-social-security-benefits

42. Melin P. Member States' social security agreements with India. Eur J Soc Secur. 2018;20(2):173-87.

43. Holzmann R, Wels J, Dale P. Assessing Benefit Portability for Migrant Workers: Lessons learned from a review of the France-Morocco bilateral social security agreement. Washington, D.C.: The World Bank; 2016. 62 p.

44. Odasso L. Migration, amour et État : un ménage à trois. Rev Inst Sociol. 2015;85:192. 
Figure 1 Number of positive PCR tests in Japan from January 2020 to March 2021, States of Emergency and Phased Measures for Resuming International Travel

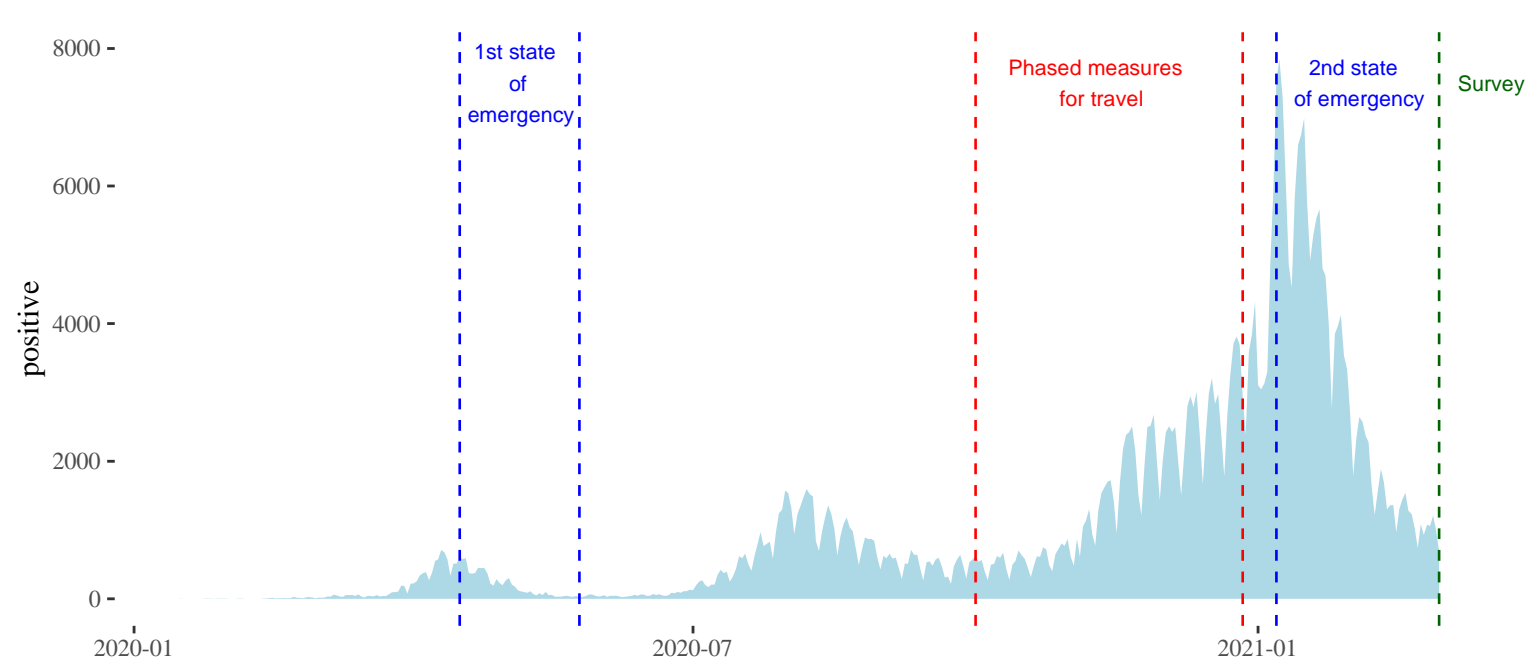

Source: Author's calculations, data retrieved from the Japanese Ministry of Health, Labour and Welfare website. Information about State of Emergency and Phased Measured for resuming international travel come from the Japanese Ministry of Foreign Affairs (MOFA). 
Table 1. Sample distribution by country of nationality and total distribution of migrants in Japan in 2017, in percent.

\begin{tabular}{lrrlrrr}
\hline Country & Stock $(2017)^{*}$ & Survey & & Country & Stock $(2017)^{*}$ & Survey \\
\cline { 1 - 2 } China & 31.43 & 0.00 & & Bangladesh & 0.56 & 0.63 \\
Korea. Rep. & 25.17 & 0.00 & Pakistan & 0.54 & 0.21 \\
Philippines & 10.13 & 5.23 & Sri Lanka & 0.45 & 0.00 \\
Brazil & 8.78 & 1.26 & France & 0.43 & 7.32 \\
Vietnam & 3.50 & 0.00 & Malaysia & 0.39 & 1.05 \\
Peru & 2.91 & 0.21 & Russian Federation & 0.36 & 1.05 \\
United States & 2.54 & 25.52 & Germany & 0.28 & 6.90 \\
Thailand & 2.00 & 0.63 & Iran, Islamic Rep. & 0.26 & 0.00 \\
Indonesia & 1.32 & 3.97 & Argentina & 0.19 & 0.63 \\
India & 1.09 & 5.02 & Other & 5.63 & 24.69 \\
United Kingdom & 0.88 & 9.00 & & & 100 & 100 \\
Canada & 0.59 & 5.65 & Sum & $2,357,707$ & 478 \\
Australia & 0.57 & 1.05 & $N=$ & &
\end{tabular}

Source: * World Bank Migration Matrix (2017), author's calculation.

More information about WB matrixes is available in (13) 
Figure 2. Distributions of self-reported change in physical health, quality of life, sleep quality and level of stress
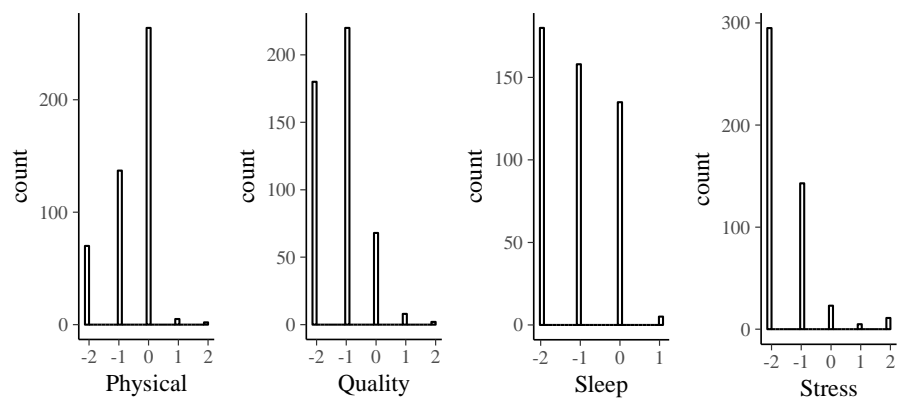
Figure 3. Bayesian ordered logit regression for physical health, quality of life, sleep quality and level of stress outcomes
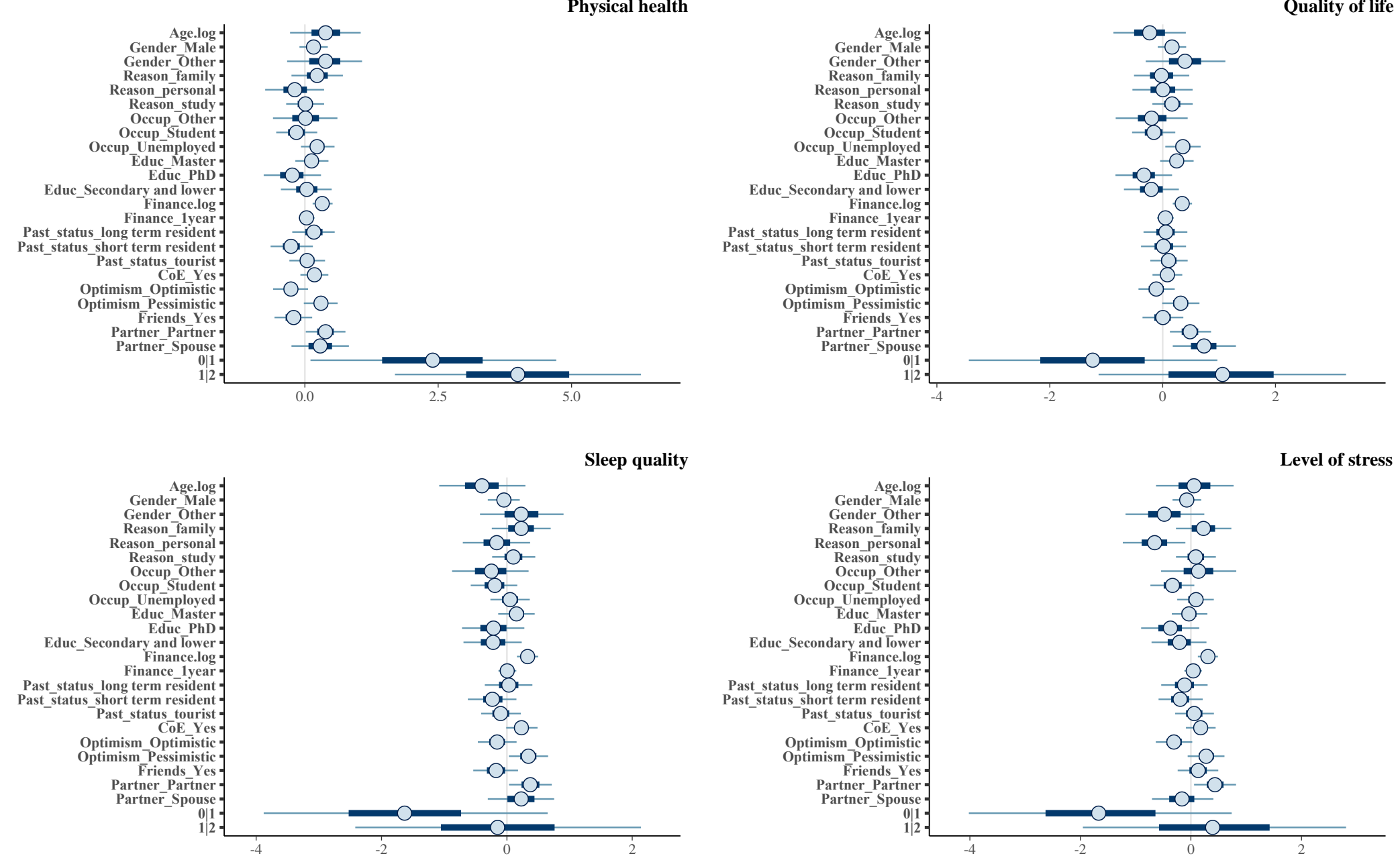

Note: Thresholds calculated as the sample average posterior predictive distribution of the outcome variable and Monte Carlo standard error. Calculation made using the 'stan polr' R-package. Estimates are in logit. CI are calculated at 95 and 90 per cent. Five missing variables where excluded from the models. The estimates can be interpreted as follow: values higher than 0 indicates higher odds (log odds) of being in the highest modalities of the dependent variable (versus the lowest). Similarly, estimates under 0 indicate lower odds of being in the highest modalities. 


\section{Acknowledgment}

The author would like to thank the respondents who have answered this survey, particularly those in financial, professional or emotional trouble.

\section{Conflict of interest}

None declared. 